\title{
Children in care: are social workers abusing their authority?
}

\author{
R C Benians Consultant Psychiatrist, Ealing Child Guidance Service
}

\section{Editor's note}

This paper is a plea, from a child psychiatrist, for greater consultation between professionals who have skills in promoting the welfare of children, namely social workers, teachers and doctors. Three much shortened case histories are presented where insufficient consultation between social workers and child psychiatrists led, in the author's opinion, to abuse of social work authority and therefore to unnecessary professional and legal conflict. The paper is based on a lecture given under the auspices of the London Medical Group.

The short answer to the question 'Are social workers abusing their authority?' is: 'Yes, very occasionally they are'. However, let us not forget that every local authority social worker is continually walking a tightrope with allegations of neglect on the one hand and of interference on the other. Many social workers in local authorities have experience of working with disadvantaged children from disadvantaged families. Other social workers may neither have such experience nor be sufficiently well advised by their managers to obtain support from other professionals such as child and family psychiatrists. Child and family psychiatrists are at present few in number; there are fewer than five hundred in practice throughout the United Kingdom and many of these are only part-time. Child and family psychiatry represents centuries of medical expertise concerned with children's emotional development and the quality of their interpersonal relationships. Children need an ability to relate not only during childhood and adolescence, but also throughout adulthood.

I now present three cases which include an example of failure to thrive, non-accidental injury and nonattendance at school.

\section{Case 1: failure to thrive}

This girl was third of four children born to Sikh parents who had for years lived in England in a large

\section{Key words}

Social work; child welfare; social services; child psychiatry; child abuse; non-accidental injury; non-attendance at school. city as respected members of their community although the father's occupation was unskilled. At $\widehat{\varnothing}$ birth she weighed under three pounds, labour starting $\vec{\circ}$ at the 34th week when the mother fell in the kitchen $\omega$ burning her face. Following her birth she spent three $\vec{\omega}$ months in the special care baby unit, but when she ${ }^{\omega}$ went home she did not thrive. On account of her failure은 to thrive she was re-admitted to hospital five times, at $\overrightarrow{ }$ 18 months, 2 years, 5, 7 and 9 years.

Between admissions she gained very little weight. $\frac{\mathbb{D}}{\mathbb{C}}$ During the first admission rickets was noted. $\stackrel{\mathbb{D}}{3}$ Following the second admission she was fostered for ${ }^{\infty}$ some months because it was felt she needed to be cared ${ }_{-}^{-}$ for away from her family and she gained some weight $\stackrel{\infty}{\infty}$ Aged five she was not sent to an ordinary school, bet ${ }^{+}$ placed instead in a day school for delicate children. such schools attention is paid amongst other things enhancing diet. She still did not grow adequately. When aged 8 she was seen by an educational 2 psychologist who found she had not begun to read $\stackrel{\mathbb{Q}}{\mathscr{Q}}$ confidently. Her school attendance had always been $\overrightarrow{\overrightarrow{0}}$ patchy whenever she lived at home. At the age of nine 3 she was again in hospital and her paediatrician and the Social Services Department decided they must act. A Place of Safety Order was taken and she was placed in a children's home from which she continued to attend $\widehat{\phi}$ her own school and visit her family. Because of the $\frac{\sigma}{7}$ failure to thrive and her poor performance at school a decision was taken to find foster parents for her, $a$ o decision that was challenged not only by her family, $₹$ but also the local Sikh community. I was asked by음 solicitors for the child to interview her and her family $>$ and to give an opinion. The parents told me they loved their daughter and she them. When they introduced $\tilde{N}$ me to her brothers and sisters I noticed that all four ${ }^{\circ}$ children were small for their age. The Sikh community leaders pointed out that Sikh girls had to complete $\tilde{\omega}$ certain ceremonies before certain birthdays to become $\bar{O}$ acceptable adults in their community. It was fearedo that if she lived in a children's home or with foster $\mathbb{}$ parents she would be denied these rituals and thus $\stackrel{\text { ? }}{+}$ grow up neither Sikh nor English. The community had 0 failed to discover foster parents amongst themselves. $\frac{P}{P}$ The parents told me she had frequently refused to do what they wanted and this included eating. Each $\stackrel{\mathbb{Q}}{\varrho}$ separation from them had exacerbated this difficulty. 
She would on occasions withhold speech and they recalled several episodes of soiling. My interviews with the girl confirmed her small size, her unforthcomingness, and her lack of confidence. Nevertheless, the conversation she was able to sustain with me and the writing she added to all the pictures she drew for me (it was her idea to draw), suggested that she had more ability than she had confidence to show.

Although under the care of a paediatric team no psychiatric opinion had been asked for. Child psychiatrists deal every day with children who do not know how to express their feelings and who are consequently so unsure of themselves that they can scarcely join in anything around them. This child's poor start in life and repeated separations from home would have been sufficient to account for the relationship difficulties between her and her parents. And yet an emotional, or relationship component to her difficulties had not been mentioned by social workers, doctors, teachers or the psychologist. I recommended that if the court felt she must be away from home that she should be considered for a place in a special residential school for children who are slow learners and who have behaviour disorders. In such a school she would maintain intermittent contact with her parents and her community and its rituals whilst receiving specialist help for her education as well as her problems of relationship. These suggestions were not accepted by the social services or another child psychiatrist, whom they called to give evidence, who had never met the child or her family. In court the judge said it was a complicated case and that he felt a care order was the best solution.

\section{Case 2: non-accidental injury}

Case 2 was the third child of four born to a Maltese woman. The first two were born illegitimately, a different father for each, and looked after from birth by their maternal grandparents in Malta. This woman then met and married the father of her third and fourth children, an Irishman serving overseas with the British Army. The mother and father looked after her third child, a girl, who is the subject of this case history, until the fourth child was born when it was discovered that the mother was seriously ill with tuberculosis. The mother was admitted to hospital and remained there for ten months. The maternal grandparents took on the care of the fourth child in addition to the mother's first two children. The little girl, the mother's third child, was by then nearly two and was looked after by her godparents, also in Malta. When the mother recovered she and her husband moved to married quarters at an army base in England bringing with them her two youngest children, the girl by then aged about three years and the new baby, a boy aged about one year. All seemed to go well in the new setting until the girl was aged five and started to go to school, when it was discovered that she was covered with bruises of varying ages. By now the father was posted overseas and his wife was trying to cope with the children on her own with little knowledge of the English language, or English ways. The social services were alerted and the girl was taken into care on a full care order. Access was not completely severed. In fact, she was kept in occasional contact not only with her mother and brother in England, but also with her older halfsiblings, her grandparents and her godparents, who had fostered her during the mother's illness. However, she was a considerable behaviour problem in care and after a time in an observation and assessment centre was placed first in one children's home, then with foster parents who found her too difficult and spiteful to manage and then in yet another children's home.

At first the father accepted the situation as the best course for his daughter. His duties overseas prevented his return to the family except for brief periods of leave. However, when he realised his daughter was being shunted from pillar to post in care he took steps to end his duties overseas and returned home. He managed to persuade the social services that because he was now home again it would be appropriate for him and his wife to resume their daughter's care. After all, there had been no objection to him and his wife, or his wife alone, caring for the little boy. Aged about seven, the girl came home on trial successfully. The parents applied to the juvenile court to have the care order rescinded and were successful. However, the Social Services Department immediately instituted wardship proceedings in order to retain control of the child and her future. They said they were not yet satisfied that the mother and father were the best people to care for their daughter. When I made my enquiries at the request of the high court $I$ found that this girl, her brother and parents formed a surprisingly united family considering their various experiences. It was clear to me that the girl had a difficult personality and had probably proved too much of a handful for her mother, a parent virtually on her own in what was to her a foreign country, when the father was sent abroad. It was also clear that the girl's early experiences of changed parenting, added to the experiences of four complete changes of parent figures and schools whilst in care, were no less damaging to her emotional development than the beatings meted out to her by her mother had been to her physical development.

Whilst we might all agree with removing her to a place of safety in the short term, the social services did not seek any specialist help for her disturbed relationship with her mother. In fact, this case never came to a high court hearing. The social services backed down. The father took his discharge from the army so that the entire family and extended family could be reunited in Malta.

\section{Case 3: non-attendance}

Case three, a boy, lived with his mother and two younger sisters in a council flat in a large city. The 
father, in fact the boy's stepfather, had moved away and kept no contact with the family. This boy was not clever and had always been reluctant to go to school because his face was partly covered by a port-wine naevus which caused him great embarrassment. Early in his school career he came to the notice of the school medical officer because of his irregular attendance. The school medical service decided he should go to a day school for partially sighted children. His eyesight was poor in one eye, but normal in the other. However, it was felt he could benefit from attendance at a smaller school, and from the more personal attention of a special school. For a while all went well until he was about seven when again he began to miss his school bus in the mornings. This was soon after his stepfather left home. The mother was prosecuted, but was unable to attend court. His non-attendance was proved and a care order to social services was made on the grounds that his mother could not control him adequately. After a while in an observation and assessment centre, he was placed in a long-term children's home. The mother and boy were told that he would be rehabilitated if she was able to show she could manage him properly. He was to stay at the children's home and go regularly to his former school. It was hoped that he would benefit from a period of firmer control and regular school attendance. Before rehabilitation could start the mother was told she must prove herself to be reliable by conforming with social services's wish that she visit her son at the children's home at regular intervals. The mother approached the solicitor at her local law centre and demanded to have her son home. The solicitor asked if she had kept up her access to the boy in the children's home as requested by the social services. She admitted she had not because she found it difficult to travel. The solicitor decided to take the mother to the children's home and so called for her in his car. After a mile or two in busy urban traffic the mother suddenly began to scream and tried to jump out of the moving car to the consternation of the solicitor. She then revealed that she was terrified of travelling under railway bridges and that was why she refused to use buses and had never got to the children's home. By dint of skilful map-reading the solicitor found an alternative route which avoided bridges. Thus one $\stackrel{\frac{\mathbb{Q}}{\varrho}}{\mathrm{s}}$ access visit was at last made!

No one in social services seemed to have realised that $\overrightarrow{\vec{D}}$. this mother, although a reasonably competent parent? at home, was seriously limited outside the home by her $\vec{F}$ phobia of travel in general and of bridges in particular. The solicitor called me in because he felt that neither $\frac{\mathrm{C}}{0}$ the social services nor the court had ever allowed $\frac{\overline{\bar{c}}}{\overline{0}}$ sufficiently for the nature of the mother's disability. In $\vec{\sigma}$ addition, I was to discover that a Family Service Unit 0 in the neighbourhood was willing to work with the family. Consequently the juvenile court was persuaded $\vec{\circ}$ to rescind the care order at a subsequent hearing.

This case demonstrates a sad failure to recognise the $\vec{\omega}$ serious limitations imposed by agoraphobia, a common mental condition, in a young adult. Phobias affect one in twenty people. Consultation with a competent $\overrightarrow{-}$ psychiatrist could have saved that particular Social $\dot{\omega}$ Services Department acute embarrassment. It was $\vec{\omega}$ fortunate that another social work agency was close at $\omega$ hand to take on the work. The mother had no wish to 을 receive help from social workers who she felt had never $\rightarrow$ understood her and had disrupted her family unfairly, $\mathscr{\mathbb { D }}$ whereas she was pleased to have the help of a non- $\frac{}{P}$ statutory agency. Between the time of her son going $\frac{\mathbb{T}}{3}$ into care and the ending of the care order she had no professional worker to whom she felt she could turn, except her solicitor. It is impressive how songe $\infty$ solicitors effectively become the parent's main soure + of help and advice whilst acting as the child's lawyer-

Sometimes where a family has regained the care of the child it is only a matter of time before a similar crisis develops. Such crises can, and in my opinion should, be used to assist the family to see the sense of a helpful $\stackrel{\Phi}{\propto}$ measure, and to assist them to accept such a $\overrightarrow{\overrightarrow{0}}$ recommendation by treaty rather than by force of law. $\frac{3}{3}$ I believe such recommendations have a greater chance of achieving desired objectives.

There will always be some families where hard decisions have to be taken and enforced, but these $\bar{\sigma}$ three cases could have been handled more effectively $\frac{\sigma}{}$ and without alienating the families from statutory services if a fuller appraisal of family relationships had $\delta$ been made earlier by those competent to do so. 